\title{
Interrelationships among Interests, Life-History, and Educational Criteria
}

\author{
Donald H. Brush and Lyle F. Schoenfeldt \\ Rensselaer Polytechnic Institute
}

The relationship between measures of vocational interest, life history data, and two major educational criteria-performance and number of courses taken by area-was explored in a university sample of 1,900 students. Canonical correlation analysis was used to uncover and to describe the major relationships between the variable sets. The largest and most important dimension emerging was a general academic achievement dimension. Indices of variance overlap suggested that background data, rather than vocational interests, exhibited a stronger relationship with the educational criteria.

The underlying relationship between interests, background data, and various educational behaviors have, in the main, been primarily conjectural among educators and behavioral scientists. For example, little research has been generated which clarifies the complexities underlying the relationship between interest patterns and academic performance across a variety of curricular areas. Despite the prolific research resulting from interest inventories, one area that has not been adequately explored is that of interest patterns as they relate to course selection or number of courses taken in a given area.

Most interest inventory research has related to interest pattern stability (Campbell, 1966; Johansson \& Campbell, 1971), personality corre-

APPLIED PSYCHOLOGICAL MEASUREMENT Vol. 3. No. 2 Spring 1979 pp. 165-175

(c) Copyright 1978 West Publishing Co. lates (Brandt \& Hood, 1968; Drasgow \& Carkhuff, 1964), occupational prediction (Flanagan, Cooley, Lohnes, Schoenfeldt, Holderman, Combs, \& Becker, 1966; Harmon, 1969; Levine $\&$ Wallen, 1964), and studies relating particular interest scales to performance in a specific curricular area or to overall grade point average (Johnson, 1969; Lindgren, 1973; Wood \& Langevin, 1972). Although the data support the validity of occupational prediction and interest stability, the research relating to course performance and selection has received mixed reviews (Tyler, 1965). Cooley's (1967) monograph represents one of the most sophisticated examinations of the interactions among interests, abilities, and career plans; high school ability was found both to affect and to be affected by interest patterns. The number of courses taken in a particular area has not, in general, been studied with respect to interest patterns. If it is assumed that interests represent a kind of motivational construct, then it would seem to follow that there might exist a relationship between interests and depth of course work.

Biographical data represent another variable set in a noncognitive domain which has frequently been used either in conjunction with, or as an alternative to, interest inventories (Holland, 1976). For example, patterns of past behavior may illustrate motivational patterns 
that are consistent with interest predictions (Brush, 1974). In addition, it has been found that biographical data can, with a fair degree of accuracy, predict Strong Vocational Interest Blank Scores (Jones, 1970).

The disjunctiveness of the literature with respect to vocational interests, characteristics of people, and career-oriented behavior raises the need for more studies attempting to integrate these various lines of research. The present study, primarily concerned with explaining and understanding the underlying dimensions and relationships between two important noncognitive measures-interests and background-and two major educational criteria-academic performance and number of courses taken by area-is one attempt in the pursuit of this goal.

\section{Method}

\section{Subjects}

The subjects were 1,011 males and 881 females, an $80 \%$ sample of a freshman class at a southeastern university. All subjects were participants in a longitudinal study unrelated to the present research, but which involved completion of an extensive test battery shortly after enrollment.

\section{Procedure}

All subjects completed a biographical information blank (BIB) and the Strong Vocational Interest Blank (SVIB) during the first quarter of residence. The BIB used was a 389 -item questionnaire constructed with multiple-choice items in which the response options were arranged to form a continuum. Scales were formed from the items by separate principal components analyses and varimax rotations for the sex groups, which resulted in two factor sets of 19 factors each. A detailed discussion of the methodology regarding the development of the biographical inventory is available elsewhere (Schoenfeldt, 1970). For the purposes of the present research, it is worth noting that for both sexes the 19 dimensions were divided into several sets and included dimensions involving (1) parental-family relationships (e.g., parental warmth, parental control, socioeconomic status), (2) personal style (e.g., introversion, aggressiveness), (3) achievement (general achievement as well as achievement in mathematics and English), and (4) interest areas (e.g., athletic interest, scientific interest, cultural-literary interest). From the SVIB, a set of 22 homogeneous content scales, better known as basic interests, have been developed by clustering items with high intercorrelations (Campbell, Borgen, Eastes, Johansson, \& Peterson, 1968).

Academic criteria were obtained from transcript records 13 quarters (including summers) following matriculation. A computer program was developed to scan the transcript of each subject and to derive a record consisting of (1) high school grade point average (GPA), (2) Scholastic Aptitude Test (SAT) Verbal, (3) SAT Math, and (4) a profile of grades received and number of courses taken in 12 academic areas. These areas included (1) fine arts (e.g., art, drama, music), (2) languages, (3) humanities (e.g., literature, history, philosophy), (4) biological sciences (e.g., biology, botany, zoology), (5) physical science (e.g., physics, chemistry), (6) social sciences (e.g., economics, geography, psychology, sociology), (7) agriculture, (8) business, (9) education, (10) home economics, (11) speech/journalism, and (12) physical education/ROTC. The typical student completed an average of 32 courses which included courses in 7 of the 12 areas. Distributional requirements insured that virtually all students had courses in the humanities, sciences, and physical education. Other research with these academic criteria suggested that high school grades correlated as highly with college grades as college grades in one area correlated with grades in other areas (Schoenfeldt \& Brush, 1975). The SAT scores, while typically considered as indices of academic performance, were only moderately correlated with grades (19 of the 24 correlations were in the 
.20 's or lower) and defined a separate dimension.

All correlations between the interest, background, and educational criteria were based on maximum $N$ 's available, although the only area with any substantial amount of missing data was the academic performance domain. The distributional requirements mentioned earlier and the large sample size, however, ensured that data were relatively complete for most students and did not adversely affect the interpretation of the resulting dimensions.

\section{Analysis}

The desire to understand relationships among several variable sets, namely interests and background experiences in relationship to academic performance and number of courses taken, provided a natural opportunity for the application of canonical correlation analysis. Although the correlations between pairs of measures (as between a given basic interest and each successive academic performance area) may be of interest, it is difficult to think about all the possible bivariate correlations simultaneously in an effort to generalize to the nature and extent of interrelationships between the domains. The canonical procedure allows the derivation of a best linear function from among all possible linear functions in a set of variables (e.g., interest scores), while simultaneously deriving a best linear function from all possible functions of a second variable set (e.g., grades received in different areas of study) such that the function from the first set correlates maximally with that derived from the second set.

The basic comparisons studied in the present study were (1) interests vs. academic performance; (2) interests vs. number of courses taken; (3) biographical data vs. academic performance; and (4) biographical data vs. number of courses taken. Since the biographical dimensions were slightly different for males and females, the biographical-performance and biographical- courses comparisons were run separately by sex, resulting in a total of six comparisons in all.

Canonical variates were tested for significance, and those roots needed to explain the relationship between the two sets in each analysis were described. Given the large sample size, it would be expected that numerous canonical roots would be significant. For reasons of parsimony and interpretability, roots with canonical correlations $\left(R_{c}\right)$ of less than .30 were not discussed, even if they were statistically significant. Interpretations of the roots were based on the correlations of the variables in that set with the canonical variate. Thus, the interpretation is identical to the structure resulting from a factor analysis. The loadings are correlations between the original variables and the new canonical dimension. In addition, several variance indices were calculated including (1) the variance extracted (VE) from the data set by each canonical variate; (2) an estimate of variance redundancy (obtained by multiplying $R_{c}^{2}$ by VE); (3) the redundancy (proportion of data set variance known, given another data set) attributable to each variate; and (4) a redundancy efficiency index (RE) for comparing the amount of variate redundancy to variance extracted. The RE index discloses the decreasing efficiency in the extraction of redundant variance with each successive root and is calculated by dividing the redundancy by the variance extracted (Wood, 1972).

\section{Results}

\section{Interests and Academic Performance}

The first four canonical roots in the analysis (see Table 1) of SVIB scores and GPAs across the curricular areas were highly significant $(p<$ .001 ). The first canonical factor suggested that students who had high interest scores in business activities also had high grades in agriculture (which is heavily economic and managerial in its orientation at this institution). The second pair of canonical variates was defined by high loadings on art and writing interests, on one hand, and high verbal aptitude from the per- 
Table 1

Canonical Correlations, Loadings and Variance Indices:

Interests-Performance (GPA)

\begin{tabular}{|c|c|c|c|c|}
\hline \multirow[b]{2}{*}{ Scale } & \multicolumn{4}{|c|}{ Canonical $\mathrm{R}$} \\
\hline & $\mathrm{R}_{\mathrm{cl}}=.91$ & $R_{c 2}=.58$ & $R_{c 3}=.50$ & $R_{c 4}=.45$ \\
\hline \multicolumn{5}{|l|}{ Interests } \\
\hline Business Management & .40 & & & \multirow{4}{*}{-.40} \\
\hline Sales & .40 & & & \\
\hline Merchandising & .50 & & & \\
\hline Office Practices & .63 & & & \\
\hline Technical Responsibility & & & & -.43 \\
\hline Mathematics & & -.49 & .62 & \\
\hline Science & .46 & & & \multirow[b]{2}{*}{-.40} \\
\hline Mechanical & .51 & & & \\
\hline Adventure & .40 & & & \\
\hline Social Service & & & & .44 \\
\hline Religious Activities & & & & \multirow{2}{*}{.55} \\
\hline Teaching & & & & \\
\hline Art & & .60 & & \multirow{2}{*}{.47} \\
\hline Writing & & .84 & & \\
\hline \multicolumn{5}{|l|}{ GPA's } \\
\hline Language & & & & .46 \\
\hline Humanities & & & & .44 \\
\hline Social Science & & & & .40 \\
\hline Agriculture & .40 & & & \multirow[b]{2}{*}{.46} \\
\hline Education & & & .41 & \\
\hline Home Economics & & & & .64 \\
\hline Speech Journalism & & & & .45 \\
\hline H.S. GPA & & & & \multirow[t]{2}{*}{.77} \\
\hline SAT V & & .64 & & \\
\hline SAT M & & & .40 & \\
\hline Summary Data & SVIB GPA & SVIB GPA & SVIB GPA & SVIB GPA \\
\hline Variance Extracted (VE) & .089 .029 & .096 .056 & .034 .075 & .079 .165 \\
\hline Redundancy $\left(\mathrm{R}_{\mathrm{C}}^{2} \cdot \mathrm{VE}\right)$ & $.074 \quad .024$ & .032 .019 & $.008 \quad .018$ & .016 .033 \\
\hline Percent Redundancy & .569 .255 & .246 .202 & .062 .191 & .123 .351 \\
\hline Redundancy Efficiency & .831 .828 & .333 .339 & .235 .240 & .203 .200 \\
\hline
\end{tabular}

Note: Only variables with loadings greater or equal to .40 are included in the table.

formance domain, on the other. The third pair of canonical variates resulted from the relationship between a math interest dimension and a moderately high math aptitude and education grade dimension. The final canonical variate pair was defined by humanitarian interest ac- tivity (e.g., social service, teaching, religion) loadings paired with a general academic achievement factor ( 7 of the 12 GPAs had loadings $\geqslant .40$ ).

The variance extracted (VE) by each variate from its respective data set ranged from $3 \%$ to 
$17 \%$. It should be noted that the VE did not necessarily proceed from high to low. For example, the VE for the interests $R_{\mathrm{c} 2}$ was the highest, while the VE for $R_{c 1}$ and $R_{c 4}$ was higher than $R_{c 3}$. On the other hand, the VE for the grades $R_{c 3}$ became larger with each succeeding root extracted. Thus, there appeared to be no necessary relationship between the magnitude of $R_{c}^{2}$ and VE. In other words, a canonical variate may extract more variance from a data set than any other variate within that data set and not relate as highly to its counterpart variate in the other set.

The RE range of $1 \%$ to $7 \%$ was far below that for VE. Given either the GPA set or the SVIB set, only $9 \%$ and $13 \%$ in variance, respectively, can be accounted for by the other set. The magnitude of the $R_{c}$ 's, ranging from .91 to .45 , would suggest much greater overlap than actually existed. Also, although the percent of redundancy did not steadily decrease, the ratio of redundancy to VE did decrease progressively.

\section{Interests and Number of Courses Taken}

Three significant canonical roots $(p<.001)$ ranging between .65 and .41 were extracted from the data domains of interest and number of courses taken as seen in Table 2. The most salient dimensions could be characterized as humanitarian vs. science/technical $\left(R_{c 1}\right)$, science vs. business $\left(\boldsymbol{R}_{\mathrm{c} 2}\right)$, and communication $\left(\boldsymbol{R}_{\mathrm{c} 3}\right)$. Although the $R_{c}$ 's of the analysis were smaller than for the interest-performance canonical analysis, the total variance extracted from each set was slightly more than that of the interest-performance analysis ( $35 \%$ and $37 \%$ vs. $30 \%$ and $33 \%$ ). Similarly, the amount of redundancy, given either the interest data or the number of courses data $(10 \%)$, was also comparable to the interestperformance analysis. The percent of redundancy did steadily decrease here, however. The RE indices also diminished across roots as before and were substantially lower than in the interest-performance analysis.

\section{Background Experiences and Academic Performance: Males and Females}

The canonical analyses for both males and females (Tables 3 and 4) each resulted in four significant roots ( $p<.001)$, with $R_{c}$ 's ranging from .84 to .45 and from .78 to .43 , respectively. Most notable here, for both sexes, was a large general academic achievement factor. For males, this dimension accounted for $25 \%$ and $51 \%$ of the variance extracted from the biographical and grade point averages data from the first four roots. For females, $43 \%$ and $78 \%$ of the variance extracted from the background and performance data were accounted for by the general academic achievement dimension. The first canonical dimension for males suggested that those who had high socioeconomic status (SES) also tended to have high verbal aptitudes and high grades in biological sciences. The third canonical dimension defined a high math and low verbal factor in each set of data. The fourth factor pair suggested that those students with close family relationships tended to perform well in physical activities. For females, verbal $\left(R_{c 2}\right)$ and math $\left(\boldsymbol{R}_{\mathrm{c} 4}\right)$ dimensions were defined. Additionally, the third canonical pair suggested that well-adjusted students who were either only children or came from families exhibiting high parental control tended to excel in home economic academic areas. (It will be recalled that the biographical factors were statistically defined to be orthogonal to one another. Hence, it is not surprising that there are few high loadings within the biographical set for each canonical pair.)

The degree of redundancy of the background data given the academic performance data was more than twice that of the interest scores given the performance data $(23 \%$ vs. $9 \%)$. On the other hand, the amount of redundancy of the performance data given the background data was slightly lower ( $10 \%$ males, $8 \%$ females) than that of the performance data given the interest scores (13\%). 
Table 2

Canonical Correlations, Loadings and Variance Indices: Interests and Courses

\begin{tabular}{|c|c|c|c|}
\hline \multirow[b]{2}{*}{ Scale } & \multicolumn{3}{|c|}{ Canonical $\mathrm{R}$} \\
\hline & $\mathrm{R}_{\mathrm{c1} 1}=.65$ & $R_{c 2}=.46$ & $\mathrm{R}_{\mathrm{c} 3}=.41$ \\
\hline \multicolumn{4}{|l|}{ Interests } \\
\hline Pub1ic Speaking & & & .41 \\
\hline Law/Politics & & -.46 & \\
\hline Business Management & & -.64 & \\
\hline Sales & & -.57 & \\
\hline Merchandising & & -.62 & \\
\hline Office Practices & & & -.53 \\
\hline Military Activities & -.41 & & \\
\hline Technical Responsibility & & -.52 & \\
\hline Mathematics & -.45 & & \\
\hline Science & -.44 & .61 & \\
\hline Mechanical & -.67 & & \\
\hline Nature & & .50 & \\
\hline Social Service & .56 & & \\
\hline Teaching & .48 & & \\
\hline Music & .45 & & \\
\hline Art & .72 & & \\
\hline Writing & .59 & & .58 \\
\hline \multicolumn{4}{|l|}{ Courses } \\
\hline Languages & & & .50 \\
\hline Humanities & & & .52 \\
\hline Bio. Science & & .75 & \\
\hline Physical Science & -.54 & .56 & \\
\hline Business & -.53 & -.53 & \\
\hline Education & .44 & & -.58 \\
\hline $\mathrm{S}-\mathrm{J}$ & & -.41 & \\
\hline Physical Education/ROTC & -.61 & & \\
\hline
\end{tabular}

Summary Data

Variance Extracted (VE)

Redundancy $\left(\mathrm{R}_{\mathrm{C}}^{2} \cdot \mathrm{VE}\right)$

INT. COURSES INT. COURSES

INT. COURSES

Percent Redundancy $.148 \quad .127$

$.137 \quad .135$

$.066 \quad .104$

Redundancy Efficiency

$.062 \quad .053$

$.030 \quad .029$

$.011 \quad .018$ $.602 \quad .530$

$.291 \quad .290$

$.107 \quad .180$

$.419 \quad .417$

$.219 \quad .215$

.167

.173

Note: On1y variables with loadings greater or equal to .40 are included in the table.

\section{Background Data and Number of Courses Taken: Males and Females}

Three significant canonical roots ranging from .34 to .52 and from .32 to .51 for males and females, respectively (Tables 5 and 6), were ex- tracted from the background and number of courses taken data $(p<.001)$. The canonical correlations and $R_{c}^{2}$ 's were substantially lower than those obtained between background experiences and academic performance. For males, the first canonical pair suggested that those students 
Table 3

Canonical Correlations, Loadings and Variance Indices: Male Biodata and Performance (GPA)

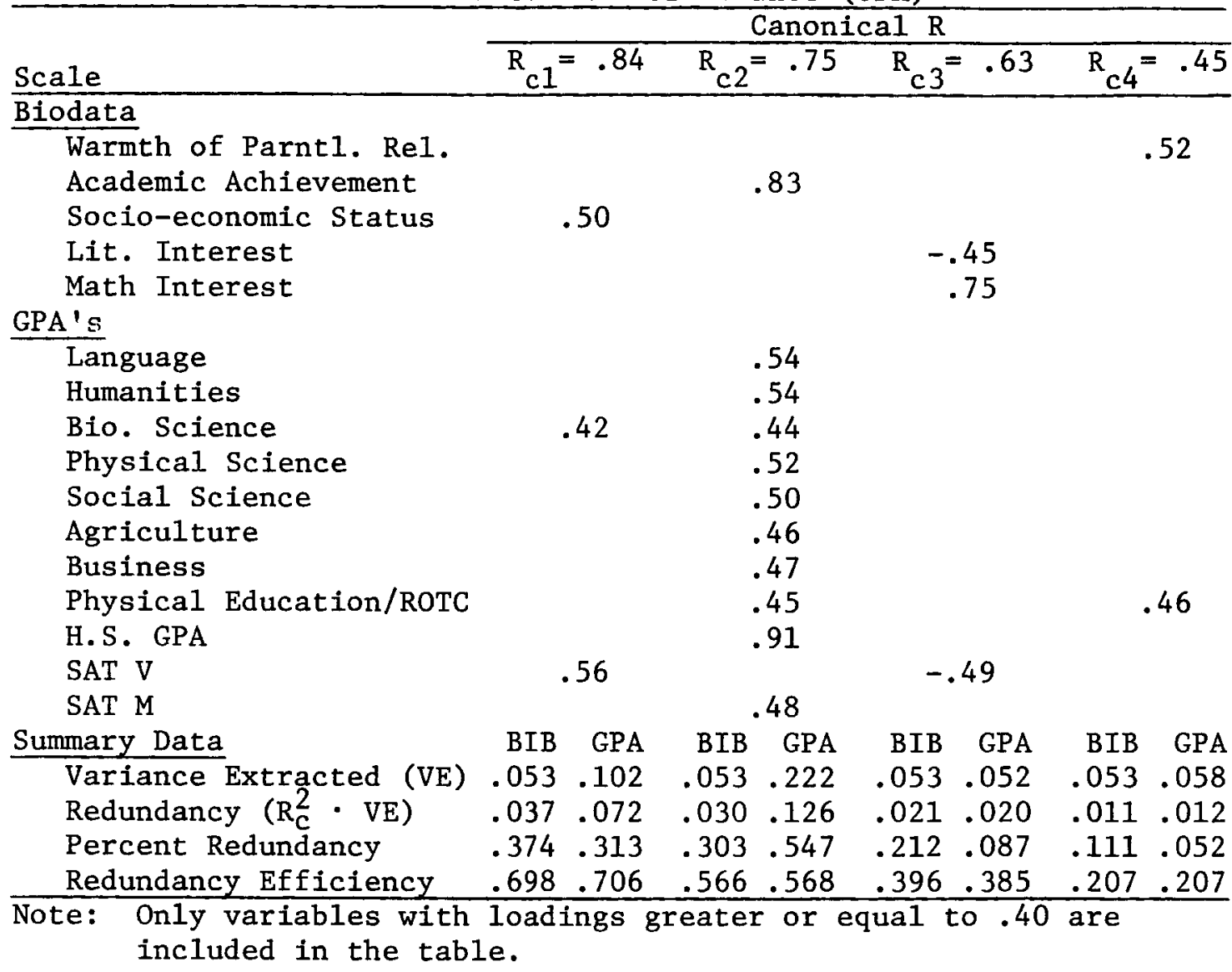

with a background in math and science tended to take more courses in the science vs. the humanities areas. The second dimension was defined by a high loading on the BIB science scale and high course loadings in areas of biological and physical science and a low loading on business courses. The third pair of roots indicated that those students who had high SES and academic achievement tended to take more courses in the humanities and social sciences.

The first canonical pair of factors for females suggested that female students who have had more experience and interests in sciences (vs. art) and math (vs. English) took more courses in the biological and physical sciences. The second pair of roots defined an underlying cultural literary interest paired with more courses in languages. The third canonical factors found that students with high academic achievement but low science backgrounds tended to take more courses in the humanities and the social sciences. The redundancy of either the background data or number of courses taken data given the other set was substantially lower than the redundancy indices for the background data and academic performance data. There was approximately one-third the amount of redundancy in the background-courses data as there was in the background-performance data. 
Table 4

Canonical Correlations, Loadings and Variance Indices: Female Biodata and Performance (GPA)

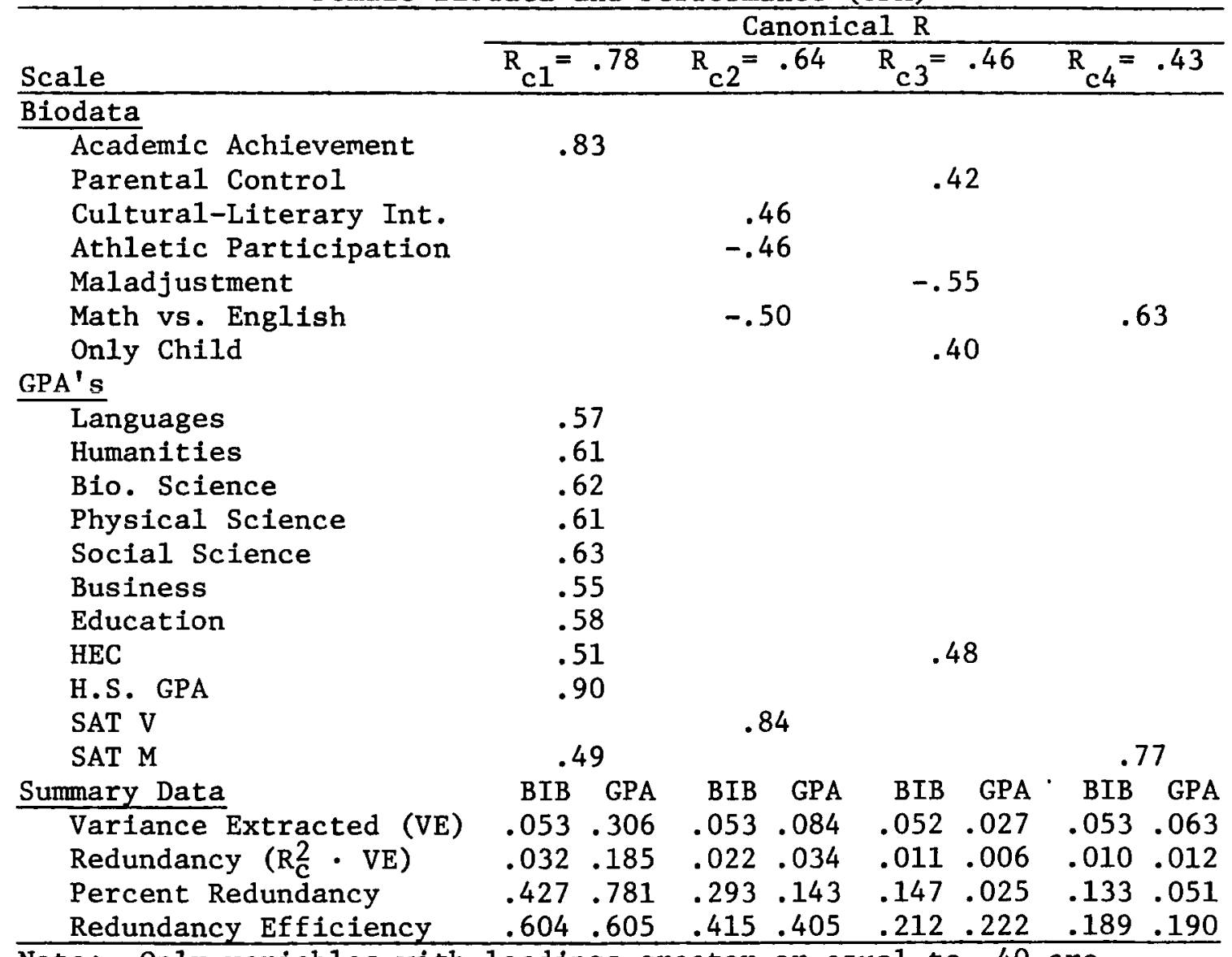

Note: Only variables with loadings greater or equal to .40 are included in the table.

\section{Discussion}

The present study was concerned with an examination of the underlying factors and the degree of the relationship between (1) interest and backgrounds, and (2) academic performance and number of courses taken in a variety of curricular areas. The most clear-cut dimensions that were similar when considering pairs of data sets were found in the relationship between biographical data and academic performance (GPAs). These were highlighted by math aptitude, verbal aptitude, and general academic achievement dimensions. The dimensions found in the other canonical analyses were either of this nature (e.g., science and writing dimensions) or such that they characterized student attributes and academic behavior (e.g., students with high SES and achievement orientation tended to take more courses in the social sciences).

The canonical correlations between paired sets of data ranged from .91 to .31 . Sixty-six percent of those correlations ranged from .65 to .40 . The highest correlations came from the performance data relating to background data and 
Table 5

Canonical Correlations, Loadings and Variance Indices: Male Biodata and Courses Taken

\begin{tabular}{|c|c|c|c|c|c|c|}
\hline \multirow[b]{2}{*}{ Scale } & \multicolumn{6}{|c|}{ Canonica1 $\mathrm{R}$} \\
\hline & \multicolumn{2}{|c|}{$\mathrm{R}_{\mathrm{cl}}=.52$} & \multicolumn{2}{|c|}{$R_{c 2}=.48$} & \multicolumn{2}{|c|}{$\mathrm{R}_{\mathrm{c} 3}=.34$} \\
\hline \multicolumn{7}{|l|}{ Biodata } \\
\hline Academic Achievement & & & & & & .49 \\
\hline Scientific Interest & & .46 & & .41 & & \\
\hline Socio-economic Status & & & & & & .42 \\
\hline Math Interest & & .45 & & & & \\
\hline \multicolumn{7}{|l|}{ Number of Courses } \\
\hline Languages & & & & .61 & & \\
\hline Humanities & & -.45 & & & & .48 \\
\hline Bio. Science & & & & .62 & & \\
\hline Physical Science & & .74 & & .54 & & \\
\hline Social Science & & & & & & .66 \\
\hline Business & & & & -.61 & & .41 \\
\hline Physical Education/ROTC & & & & & & .58 \\
\hline Summary Data & BIB & COURSES & BIB & COURSES & BIB & COURSES \\
\hline Variance Extracted (VE) & .053 & .118 & .052 & .151 & .053 & .127 \\
\hline Redundancy $\left(\mathrm{R}_{\mathrm{c}}^{2} \cdot \mathrm{VE}\right)$ & .015 & .032 & .012 & .035 & .005 & .013 \\
\hline Percent Redundancy & .469 & .400 & .375 & .438 & .156 & .162 \\
\hline Redundancy Efficiency & .283 & .271 & .231 & .232 & .094 & .102 \\
\hline
\end{tabular}

Note: Only variables with loadings greater or equal to .40 are included in the table.

interest scores. Six of 12 possible correlations were above .60 . Only one of the canonical correlations between the data on number of courses taken and background or interest data was above 60 .

Considering the number of variates estimated in each data set (19 background, 22 interest, 15 curricular), the variance extracted from the different canonical analyses seems noteworthy. Twice as much variance was extracted from the course and performance data (.39 average) as from the background data (.19 average). The amount of variance extracted from the course and performance data was about $40 \%$ more than that of the SVIB data (.27 average). The number of factors retained (three for course canonicals, four for all others) did not appreciably affect the amount of variance extracted (i.e., no relationship between the number of roots and VE).
The redundancy indices were much lower than would be expected from the size of the canonical correlations and the variance extracted from each data set. Only 3 of the 12 redundancy indices of one set given its pair exceeded $10 \%$. The single analysis with any substantial redundancy was the relationship of male and female background data with academic performance $(23 \%$ and $24 \%$ male and female, respectively, of GPA given the BIB). Based on this, it would seem reasonable that unless at least one-half of the VE for a variate pair is redundant, the description given for that pair would be tenuous at best. Only four variate pairs met this restriction: (1) the general academic achievement dimension for both the male and female background data-performance analysis; (2) the SES-verbal dimension (male BIB-academic performance); and (3) the business-agri- 
Table 6

Canonica1 Correlations, Loadings and Variance Indices: Female Biodata and Courses Taken

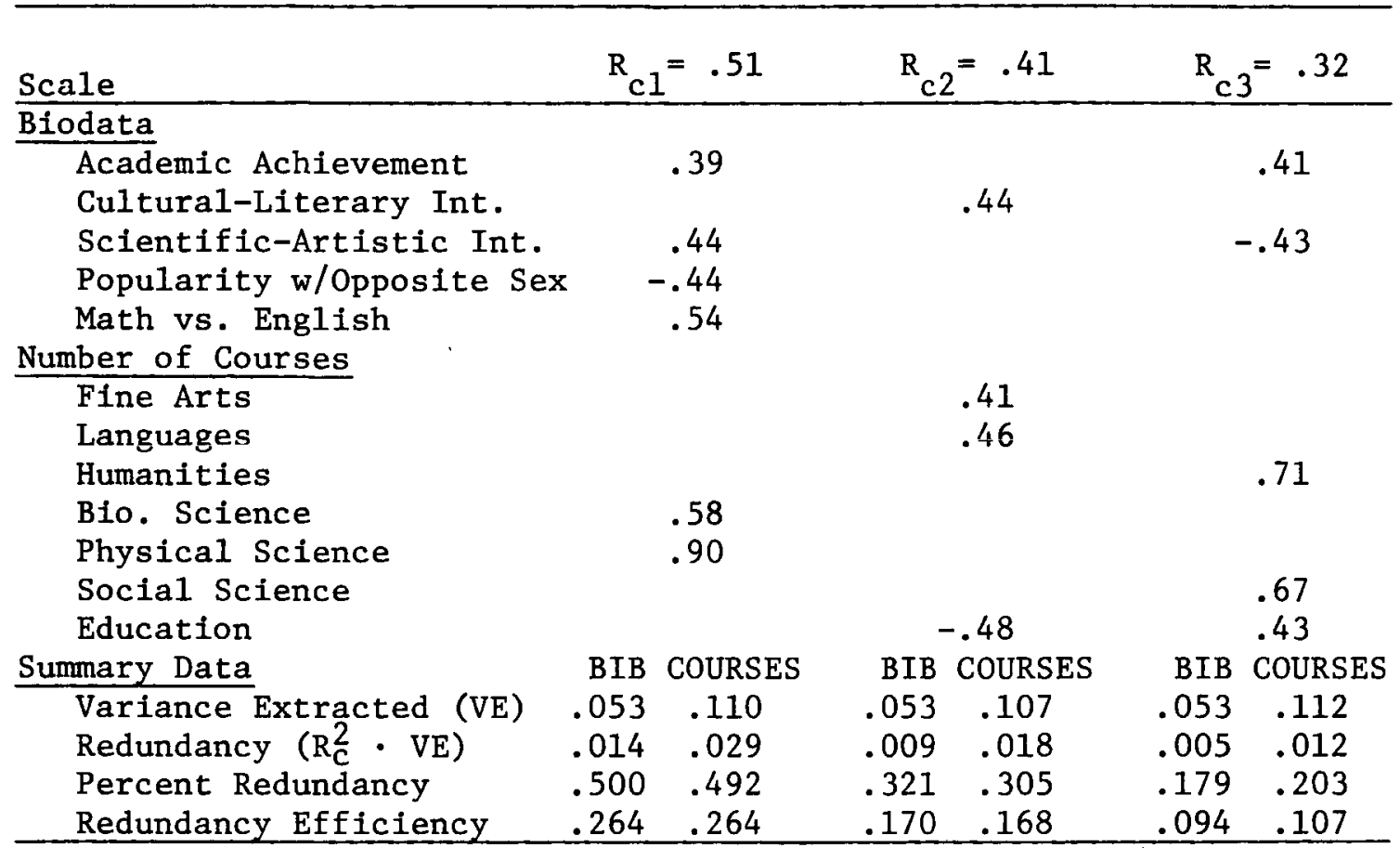

Note: On1y variables with loadings greater or equal to .40 are included in the table.

culture dimension (SVIB-academic performance). Of these, the general academic achievement dimension had the highest VE and redundancy figures. In fact, the canonical roots of academic achievement had more associated variance and redundancy than did any other canonical pair.

The results, demonstrating an important underlying dimension of academic achievement and an otherwise generally low relationship between background data and interests with academic performance and number of courses taken are supported and explained, in part, by two previous multivariate studies. Boldt (1972) and Schoenfeldt and Brush (1975) found that for most purposes, academic performance can be conceived as a generally unitary dimension. That is, factor analysis of different curricular areas tends to produce a large general academic achievement dimension. Students who tend to do well, do well in all areas; whereas students who perform poorly do poorly in all areas regardless of their interests or background experiences. A general academic achievement dimension argues for the fact that there would not necessarily be differential affinity of interest or experience for performance while in school. The generally poor results of other univariate studies cited earlier also support this notion. In the absence of within-subject variance in performance, correlations between interests or background experiences would not be expected. Similarly, when controlling for overall performance, very little meaningful variance would be left to test hypothesized relationships between independent variables and college performance. 


\section{References}

Boldt, R. F. Factor analysis of law school grades (ETS RB-73-42). Princeton, NJ: Educational Testing Service, 1973.

Brandt, J. E., \& Hood, A. B. Effect of personality adjustment on the predictive validity of the Strong Vocational Interest Blank. Journal of Counseling Psychology, 1968, 15, 547-551.

Brush, D. H. Predicting major field of study from biographical and vocational interest data: $A$ longitudinal study. Paper presented at the Southeastern Psychological Association, Hollywood, FL, May 1974.

Campbell, D. P. The stability of vocational interests within occupations over long time spans. Personnel and Guidance Journal, 1966, 44, 1012-1019.

Campbell, D. P., Borgen, F. H., Eastes, S. H., Johansson, C. B., \& Peterson, R. A. A set of basic interest scales for the Strong Vocational Interest Blank for Men. Journal of Applied Psychology Monograph, 1968, 52, (6, Pt. 2) 1-64.

Cooley, W. W. Interactions among interests, abilities, and career plans. Journal of Applied Psychology Monograph, 1967, 51 (2, Whole No. 640).

Drasgow, J., \& Carkhuff, R. R. Kuder neuropsychiatric keys before and after psychotherapy. Journal of Counseling Psychology, 1964, 11, 67-69.

Flanagan, J. C., Cooley, W. W., Lohnes, P. R., Schoenfeldt, L. F., Holdeman, R. W., Combs, J., \& Becker, S. J. Project TALENT one-year followup studies (Technical Report to the United States Office of Education, Cooperative Research Project No. 2333). Pittsburgh, PA: University of Pittsburgh, Project TALENT Office, 1966.

Harmon, L. W. The predictive power over 10 years of measured social service and scientific interests among college women. Journal of Applied Psychology, 1969, 53, 193-198.

Holland, J. H. Vocational preferences. In M. Dunnette (Ed.), Handbook of industrial and organizational psychology. Chicago: Rand McNally, 1976.

Johansson, C. B., \& Campbell, D. P. Stability of the Strong Vocational Interest Blank for Men. Journal of Applied Psychology, 1971, 55, 34-36.
Johnson, R. W. Effectiveness of SVIB Academic Interest Scales in predicting college achievement. Journal of Applied Psychology. 1969, 53, 309-316.

Jones, E. L. The affinity of subgroups for vocational interests. Unpublished master's thesis. University of Georgia, Athens, GA, 1970.

Levine, P. R., \& Wallen, R. Adolescent vocational interests and later occupation. Journal of Applied Psychology, 1954, 38, 428-437.

Lindgren, H. C. Strong's psychologist scale and course grades in psychology. Perceptual and Motor Skills, 1973, 36, 58.

Schoenfeldt, L. F. Life experience as a moderator in the prediction of educational criteria. Paper presented at the meeting of the American Educational Research Association, Minneapolis, March 1970.

Schoenfeldt, L. F., \& Brush, D. H. Patterns of college grades across curricular areas: Some implications for GPA as a criterion. American Educational Research Journal. 1975, 12, 313-321.

Tyler, L. E. The psychology of human differences (3rd ed.). New York: Appleton-Century-Crofts, 1965.

Wood, D. A. Toward the interpretation of canonical dimensions. Multivariate Behavior Research, $1972,7,477-482$.

Wood, D. A., \& Langevin, M. J. Moderating the prediction of grades in freshman engineering. Journal of Educational Measurement, 1972, 9, 311-320.

\section{Acknowledgments}

This research was supported in part by the National Institutes of Child Health and Human Development under Research Grant 5-R01-HD04135, William A. Owens, Principal Invesigator.

\section{Author's Address}

Send requests for reprints or additional information to Donald H. Brush, School of Management, Rensselaer Polytechnic Institute, Troy, NY 12181. 